\title{
MONITORAMENTO DE VARIÁVEIS DE QUALIDADE DA ÁGUA DO HORTO OURO VERDE - CONCHAL - SP
}

\section{LARA F. BUENO ${ }^{1}$, JOÃO A. GALBIATTI ${ }^{2}$, MAURÍCIO J. BORGES ${ }^{3}$}

RESUMO: O presente trabalho foi desenvolvido em área do Horto Ouro Verde, de propriedade da International Paper do Brasil, localizado no município de Conchal - SP, tendo por objetivo monitorar algumas variáveis de qualidade da água em duas condições do uso do solo (mata nativa e eucalipto). Para tanto, coletou-se água mensalmente em seis pontos ao longo do curso d'água, de maneira representativa dos diferentes usos do solo. As variáveis analisadas foram temperatura (T), oxigênio dissolvido (OD), matéria orgânica (MO) e potencial hidrogeniônico $(\mathrm{pH})$. Foram encontradas diferenças significativas na matéria orgânica para os pontos P3 (mata nativa) e P6 (eucalipto), e no oxigênio dissolvido para os pontos P1 (mata nativa) e P6 (eucalipto), e quando comparadas às médias do somatório dos efeitos em cada tipo de manejo do solo, não houve diferenças significativas para todas as variáveis estudadas.

PALAVRAS-CHAVE: qualidade da água, floresta nativa, eucalipto.

\section{MANAGEMENT OF WATER QUALITY IN OURO VERDE GARDEN, CONCHAL - SP, BRAZIL}

\begin{abstract}
This work was carried out at the Brazil's International Paper Property - Ouro Verde Garden - Conchal - SP, aiming to monitor some variables of water qualities in two soil conditions (native forest and eucalyptus). Thus, monthly, water was collected at six points throughout the water course in order to represent the different soil occupations. The analyzed variables were: temperature $(\mathrm{T})$, dissolved oxygen (DO), organic matter $(\mathrm{OM})$ and hydrogenic potential $(\mathrm{pH})$. Significative differences were found among the means of OM to the P3 point (native forest) and P6 (eucalyptus) and to DO of P1 point (native forest) and P6 (eucalyptus). When the sum of the effect in each soil conditions was compared no significant differences were observed for all studied variables.
\end{abstract}

KEYWORDS: water quality, native forest, eucalyptus.

\section{INTRODUÇÃO}

O crescimento demográfico e o desenvolvimento socioeconômico são freqüentemente acompanhados de aumentos na demanda por água, cuja quantidade e qualidade são de fundamental importância para a saúde e desenvolvimento de qualquer comunidade.

O tipo de cobertura vegetal implica distintos comportamentos nos atributos do solo e da água, sendo que a remoção das florestas tem causado aumento significativo dos processos que levam à degradação de imensas áreas, com prejuízos à hidrologia e à biodiversidade. RIZZI (1981) aborda aspectos da importância das florestas nativas na produção e conservação dos mananciais hídricos, com funções de interceptar a água da chuva, proporcionar condições ótimas de infiltração e reduzir o escoamento superficial.

\footnotetext{
${ }^{1}$ Eng ${ }^{\mathrm{a}}$ Agrônoma, Mestre em Agronomia (Ciência do Solo), UNESP, Jaboticabal - SP, Fone: (0XX16) 3209.2637, larafb@ig.com.br

${ }^{2}$ Eng ${ }^{0}$ Agrônomo, Prof. Titular, Departamento de Engenharia Rural, UNESP, Jaboticabal - SP, galbi@ fcav.unesp.br

${ }^{3}$ Eng ${ }^{0}$ Agrônomo, Doutor em Agronomia (Produção Vegetal), UNESP, Jaboticabal - SP.

Recebido pelo Conselho Editorial em: 26-5-2004

Aprovado pelo Conselho Editorial em: 3-11-2005
} 
PIRES \& SANTOS (1995) salientam que a retirada da cobertura vegetal gera a diminuição da precipitação local, da infiltração de água e do estoque de água subterrânea, causando a erosão dos solos e o assoreamento dos corpos d'água, além da alteração nos padrões de vazão e volume dos cursos d'água. LIMA \& REICHARDT (1987) afirmam que, com a adoção de práticas adequadas de manejo, podem-se controlar as perdas de solo e nutrientes, além de preservar a qualidade das águas.

A silvicultura destaca-se como atividade crescente, cuja expressiva demanda de produtos florestais no mundo explica a expansão de terras cobertas por florestas plantadas. Essas plantações florestais caracterizam-se como forma de uso da terra capaz de introduzir distúrbios ao ecossistema; porém, no curso de seu desenvolvimento, podem promover a formação de novas estruturas e o restabelecimento das funções dos ecossistemas.

De acordo com COUTO \& DUBÉ (2001), o cultivo do eucalipto é uma alternativa de preservação da natureza, pois, a partir de 1994, as práticas silviculturais, sugeriram abolir a queima e o preparo convencional do solo. LEITE et al. (1997), em trabalhos a respeito de regime hídrico do solo, com diferentes coberturas vegetais (eucalipto, mata nativa e pastagem), constataram que o eucalipto não interferiu de modo negativo no regime hídrico do solo, quando comparado aos outros tipos de vegetação.

No Brasil, a expansão de florestas de eucalipto e pínus tem ocupado grandes áreas, sendo indispensável desenvolver estudos a respeito dos impactos que esses florestamentos podem causar nos recursos naturais água e solo. SABARA (1999), ao comparar o efeito do eucalipto e culturas agrícolas em rios, na região do Médio Rio Doce - MG, concluiu que a atividade silvicultural apresenta vantagens sobre a agricultura e pecuária, na qualidade e conservação da água.

PASSOS \& COUTO (1997) citam que os plantios florestais podem trazer aos produtores rurais benefícios na conservação do solo e da água e reduzir os impactos negativos da redução das vegetações naturais remanescentes.

MARGALEF (1994) ressalta que os vários processos que controlam a qualidade de água de um rio, fazem parte de um complexo equilíbrio, motivo pelo qual qualquer alteração na bacia hidrográfica pode acarretar alterações significativas, sendo as características físicas e químicas da água de um rio indicadores da "saúde" do ecossistema terrestre, que podem ser utilizadas para o controle e o monitoramento das atividades desenvolvidas em uma bacia hidrográfica.

Dentre as variáveis de qualidade da água, podem-se destacar a temperatura $(\mathrm{T}), \mathrm{pH}$, oxigênio dissolvido (OD) e conteúdo matéria orgânica (MO). A temperatura da água influencia na concentração de outras variáveis, como OD e MO (PORTO et al., 1991), sendo a radiação solar, segundo ARCOVA et al. (1993), a principal variável que controla a temperatura da água de pequenos rios. O pH fornece indícios sobre a qualidade hídrica (água superficial valor entre 4 e 9), o tipo de solo por onde a água percorreu e indica a acidez ou a alcalinidade da solução (MATHEUS et al., 1995). O teor de OD expressa a quantidade de oxigênio dissolvido presente no meio, sendo que a sua concentração está sujeita às variações diária e sazonal em função da temperatura, da atividade fotossintética, da turbulência da água e da vazão do rio (PALMA-SILVA, 1999), podendo reduzir-se na presença de sólidos em suspensão e de substâncias orgânicas biodegradáveis, como esgoto doméstico, vinhoto e certos resíduos industriais (MATHEUS et al., 1995). A decomposição da MO nos cursos d'água pode diminuir o teor de OD, bem como o pH da água, pela liberação de gás carbônico e formação de ácido carbônico a partir deste (PALHARES et al., 2000).

A qualidade da água é reflexo do efeito combinado de muitos processos que ocorrem ao longo do curso d'água (PETERS \& MEYBECK, 2000). De acordo com LIMA (2001), a qualidade da água não se traduz apenas pelas suas características físicas e químicas, mas pela qualidade de todo o funcionamento do ecossistema. 
Em função dessas considerações, desenvolveu-se este trabalho que teve como objetivo estudar algumas variáveis de qualidade da água do Horto Ouro Verde - Conchal - SP, considerando a cobertura vegetal com eucalipto e com mata nativa.

\section{MATERIAL E MÉTODOS}

A área de estudo está situada no Horto Ouro Verde, pertencente a International Paper do Brasil e localizada no município de Conchal - SP, nas coordenadas $22^{\circ} 17^{\prime} 52^{\prime \prime} \mathrm{S}$ e $47^{\circ} 06^{\prime} 16^{\prime \prime} \mathrm{W}$. O clima da região é classificado como sendo do tipo Cwa (sistema Köeppen), tropical mesotérmico brando e úmido, temperatura média no mês mais quente e mais frio próximas de $22^{\circ} \mathrm{C}$ e $18{ }^{\circ} \mathrm{C}$, respectivamente, sendo a altitude média de $578 \mathrm{~m}$. A topografia apresenta locais diferenciados entre plano ou semiplano, com poucas áreas de encosta, com altitude máxima de $800 \mathrm{~m}$. O solo apresenta características hidromórficas, representado por horizontes Glei Húmico ou Pouco Húmico, dependendo das variações da microtopografia. A formação vegetal predominante da área em estudo caracteriza-se como mata mesófila semidecidual ribeirinha, com influência fluvial sazonal, e as principais famílias encontradas quanto ao número de espécies foram Myrtaceae, Fabaceae e Euphorbiaceae (SRINGUETTI, 2001).

A área de estudo compreende 1.145 ha, sendo 91 ha de reserva legal; 198 ha de áreas de preservação permanente e 856 ha de plantios de eucalipto. Os locais de coleta de água foram definidos levando em consideração o tipo de cobertura vegetal (mata nativa e eucalipto) em diferentes condições ambientais da área, constituindo-se de água superficial (a $30 \mathrm{~cm}$ de profundidade), coletada na parte central da calha do canal, em seis pontos assim distribuídos: P1, P2 e P3 - água em áreas protegidas por vegetação nativa; e P4, P5 e P6 - água em áreas de plantio de eucalipto (Figura 1).

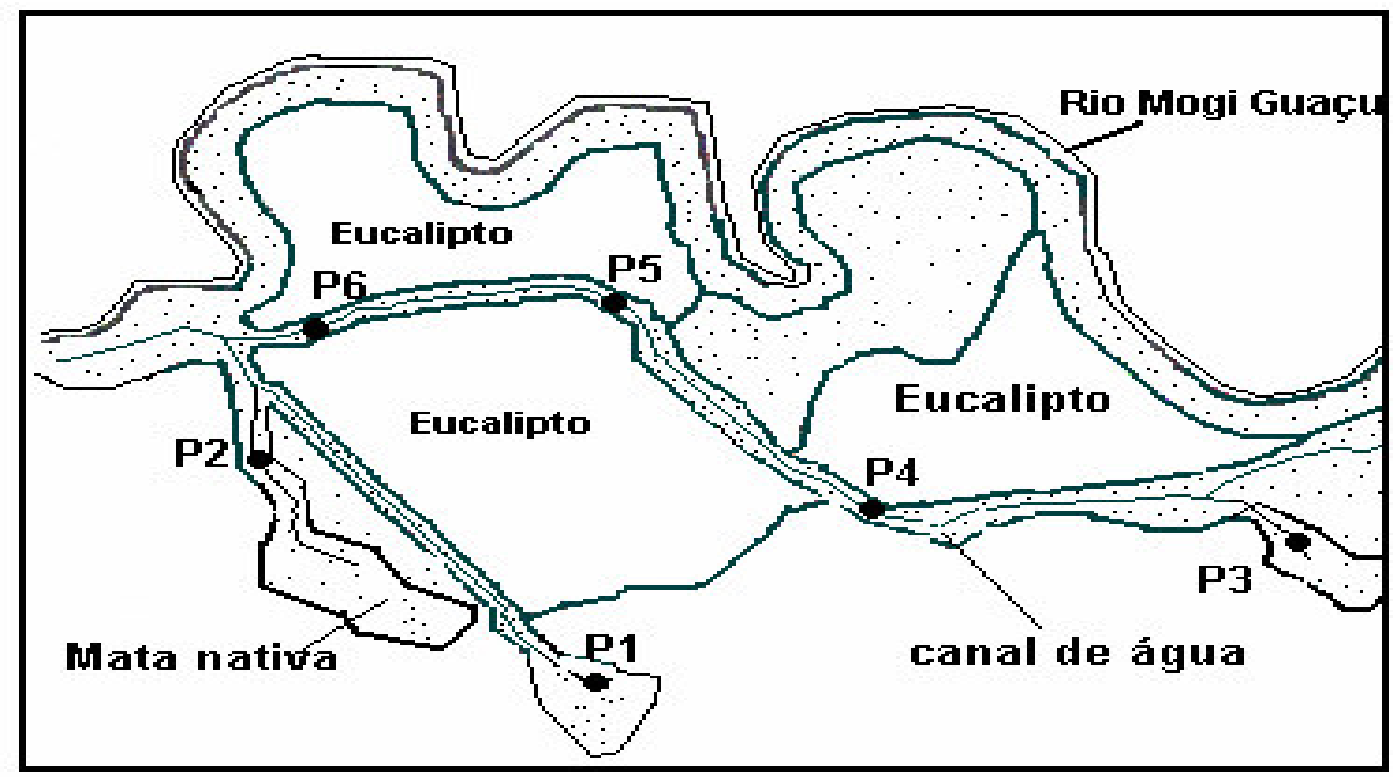

FIGURA 1. Mapa do Horto Ouro Verde - Conchal - SP, com a localização dos pontos de coleta d’água.

As amostras de água foram coletadas com auxílio de balde atado a uma corda ou mergulhando o frasco de coleta diretamente na massa líquida, no ponto mais central do curso d'água, sendo os frascos abertos no momento da amostragem e fechados a seguir. Coletou-se água por um período de seis meses, de junho a novembro de 2003, sendo o horário da coleta entre 8 e 10 horas da manhã. A temperatura da água foi medida no local da amostragem com termômetro de mercúrio. Os demais parâmetros foram analisados em laboratório, sendo o $\mathrm{pH}$ determinado por meio de leitura em potenciômetro digital, e a MO e OD, pelo método Winkler (APHA, 1995). 
Utilizou-se do programa SAS para testar a hipótese de haver diferenças significativas entre as duas condições de uso de solo e entre os pontos de coleta de água para cada variável monitorada.

\section{RESULTADOS E DISCUSSÃO}

Os valores médios obtidos da temperatura e do pH da água estão expressos na Tabela 1.

TABELA 1. Valores médios da temperatura e do $\mathrm{pH}$.

\begin{tabular}{ccc}
\hline Pontos de Coleta & $\mathrm{T}\left({ }^{\circ} \mathrm{C}\right)$ & $\mathrm{pH}$ \\
\hline P1 & 21,8 a & $6,0 \mathrm{a}$ \\
P2 & 20,4 a & $6,3 \mathrm{a}$ \\
P3 & 23,7 a & 5,7 a \\
P4 & 20,0 a & 5,9 a \\
P5 & 22,2 a & 5,9 a \\
P6 & 22,7 a & $6,3 \mathrm{a}$ \\
\hline
\end{tabular}

Para cada coluna, médias seguidas com a mesma letra não diferem entre si, de acordo com o teste de Duncan (taxa global de erro $\alpha=0,05)$. P1, P2, P3 - áreas de mata nativa e P4, P5, P6 - áreas de eucalipto.

Observa-se que os valores médios da temperatura da água variaram de 20,4 a $23,7^{\circ} \mathrm{C}$ e de 20,0 a $22,7{ }^{\circ} \mathrm{C}$, respectivamente, para os trechos de mata nativa e eucalipto. SABARA (1999), estudando córregos no médio Rio Doce - MG, encontrou valores de temperatura da água variando de 17,1 a $26,6^{\circ} \mathrm{C}$ (plantios florestais - eucalipto) e de 14,2 a $25,8^{\circ} \mathrm{C}$ (pastagens e agricultura), concluindo que o comportamento da temperatura da água foi afetado pelo uso do solo, com tendência de apresentar menores valores nas áreas florestais (eucalipto), provavelmente pela condição de cobertura dos córregos, enfatizando o papel significativo da vegetação ciliar.

Observou-se que a temperatura da água não apresentou diferenças significativas entre os pontos de coleta do Horto Ouro Verde. Ao se respeitar a faixa de preservação permanente no manejo adotado para a exploração do eucalipto (pontos P4, P5 e P6), nos canais de drenagens desenvolveu-se uma cobertura vegetal com predomínio de gramíneas, a qual conferiu proteção contra a radiação solar, semelhante à proteção proporcionada pela mata nativa (pontos P1, P2 e P3). ARCOVA et al. (1993) afirmam que a principal variável que controla a temperatura da água de pequenos rios, é a radiação solar. Segundo BRANCO (1986), a capacidade de penetração de radiação solar em ambiente aquático depende da quantidade de material suspenso presente na massa líquida.

Os valores de $\mathrm{pH}$ (Tabela 1 ) nos trechos sob vegetação nativa e sob o cultivo de eucalipto variaram, respectivamente, de 5,7 a 6,3 e 5,9 a 6,3, não apresentando diferenças significativas quanto ao tipo de uso do solo para o pH da água nos pontos de coleta. CASTRO (1980), ao estudar a influência da cobertura vegetal na qualidade da água, em duas microbacias hidrográficas na região de Viçosa - MG, sendo uma de uso agrícola e outra de uso florestal, identificou, respectivamente, $\mathrm{pH}$ de 5,6 a 6,8 e de 5,5 a 6,5. RANZINI (1990), em microbacia reflorestada por eucalipto no Vale do Paraíba - SP, encontrou valores para pH entre 5,6 e 6,3. ARCOVA et al. (1993) encontraram, em uma microbacia, valores de $\mathrm{pH}$ entre 5,8 e 6,5. OLIVEIRA (1989), em estudos sobre a qualidade da água em diferentes coberturas vegetais (pínus, eucalipto, café, pastagem e mata nativa), encontrou valores de $\mathrm{pH}$ entre 5,5 e 5,6.

Em geral, em águas superficiais, o pH é alterado pelas concentrações de íons $\mathrm{H}^{+}$originados da dissociação do ácido carbônico, que geram baixos valores de pH (ESTEVES, 1988). Esse ácido carbônico, nos corpos d'água, é resultante, segundo BRANCO (1986), da introdução de gás carbônico pelas águas de chuva, ar atmosférico, matéria orgânica do solo e, principalmente, matéria orgânica que é consumida e oxidada nas águas. 
Observando-se a Tabela 2, verifica-se que os valores médios OD variaram de 3,11 a 4,47 mg L $\mathrm{m}^{-1}$ e de 2,78 a 3,61 $\mathrm{mg} \mathrm{L}^{-1}$ para os trechos de mata nativa e eucalipto, respectivamente. Comparando-se as médias obtidas para as variáveis OD e MO, obtiveram-se diferenças significativas entre os pontos de coleta de água: P1 e P5 para OD e entre P3 e P6 para MO (Tabela 2).

TABELA 2. Valores médios obtidos do OD e da MO da água, em ordem decrescente de valores obtidos.

\begin{tabular}{cccc}
\hline Pontos de Coleta & OD $\left(\mathrm{mg} \mathrm{L}^{-1}\right)$ & Pontos de Coleta & MO $\left(\mathrm{mg} \mathrm{L}^{-1}\right)$ \\
\hline P1 & $4,47 \mathrm{a}$ & P6 & $4,47 \mathrm{a}$ \\
P4 & $3,61 \mathrm{ab}$ & P1 & $3,23 \mathrm{ab}$ \\
P6 & $3,42 \mathrm{ab}$ & P5 & $2,87 \mathrm{ab}$ \\
P2 & $3,35 \mathrm{ab}$ & P4 & $2,85 \mathrm{ab}$ \\
P3 & $3,11 \mathrm{ab}$ & $\mathrm{P} 2$ & $2,78 \mathrm{ab}$ \\
P5 & $2,78 \mathrm{~b}$ & $\mathrm{P} 3$ & $1,40 \mathrm{~b}$ \\
\hline
\end{tabular}

Para cada coluna, médias seguidas com a mesma letra não diferem entre si, de acordo com o teste de Duncan (taxa global de erro $\alpha=0,05)$. P1, P2, P3 - áreas de mata nativa e P4, P5, P6 - áreas de eucalipto.

Ocorreu correspondência negativa entre estas variáveis para estes pontos, como resultado da atividade dos organismos de respiração aeróbica que, continuamente, utilizam os materiais orgânicos como fonte de alimento, oxidando-os na respiração a fim de liberar energia neles contida, consumindo, assim, oxigênio dissolvido (BRANCO, 1986). Assim, considerando a comparação entre os pontos de coleta, em áreas de mata nativa, obtiveram-se os maiores valores médios de OD e, nas áreas de eucalipto, os maiores valores médios de MO, sendo essa diferença entre as duas condições de uso de solo, reflexo das técnicas de manejo. Resultados estes confirmados por CARVALHO et al. (2000) que afirmam que o excesso de MO na água ocasiona a diminuição do teor de OD e que, no processo de decomposição, dentro do ambiente aquático, há consumo de oxigênio.

Comparando-se as médias da somatória dos efeitos em cada tipo de uso do solo (Tabela 3 ) em todo o período de estudo, não se observaram diferenças significativas; portanto, o comportamento das variáveis $\mathrm{T}, \mathrm{pH}, \mathrm{OD}$ e $\mathrm{MO}$ foi semelhante estatisticamente para o tipo de uso do solo (mata nativa e eucalipto). A qualidade da água é reflexo do efeito combinado de muitos processos que ocorrem no curso d'água (PETERS \& MEYBECK, 2000). De acordo com LIMA (2001), a qualidade da água não se traduz apenas pelas suas características físicas e químicas, mas pela qualidade de todo o funcionamento do ecossistema.

TABELA 3. Dados das variáveis T, pH, OD e MO da água, nas duas condições estudadas (mata nativa e eucalipto).

\begin{tabular}{ccccc}
\hline Cobertura Vegetal & $\mathrm{T}\left({ }^{\circ} \mathrm{C}\right)$ & $\mathrm{pH}$ & $\mathrm{OD}\left(\mathrm{mg} \mathrm{L}^{-1}\right)$ & $\mathrm{MO}\left(\mathrm{mg} \mathrm{L}^{-1}\right)$ \\
\hline Mata Nativa & $22,2 \mathrm{a}$ & $6,07 \mathrm{a}$ & $3,65 \mathrm{a}$ & $2,47 \mathrm{a}$ \\
Eucalipto & $22,7 \mathrm{a}$ & $6,01 \mathrm{a}$ & $3,27 \mathrm{a}$ & $3,49 \mathrm{a}$ \\
\hline
\end{tabular}

Para cada coluna, médias seguidas com a mesma letra não diferem entre si, de acordo com o teste de Duncan (taxa global de erro $\alpha=0,05)$.

\section{CONCLUSÕES}

Os valores encontrados para a temperatura e $\mathrm{pH}$ da água não apresentaram diferenças significativas entre os pontos de coleta e o tipo de uso do solo. Os maiores valores de matéria orgânica e oxigênio dissolvido na água foram encontrados nas áreas de eucalipto e mata nativa, respectivamente. Ocorreram diferenças significativas entre os pontos de mata nativa e eucalipto para essas variáveis. 
A comparação entre a soma das médias dos efeitos para cada tipo de cobertura vegetal não apresentou diferenças significativas para as variáveis estudadas.

Nas condições deste caso específico, a cobertura vegetal foi responsável pela falta de variações da temperatura da água, influenciando nas demais variáveis (OD, $\mathrm{MO}$ e $\mathrm{pH})$ e sugerindo que o manejo no uso do solo é fundamental para a qualidade da água.

\section{REFERÊNCIAS}

AMERICAN PUBLIC HEALTH ASSOCIATION (APHA). Standard methods for the examination of water and wastewater. $19^{\text {th }}$ ed. Washington: American Water Works Association Environment Federation, 1995. $1.268 \mathrm{p}$.

ARCOVA, F.C.S.; CESAR, S.F.; CICCO, V. Qualidade da água e dinâmica de nutrientes em bacia hidrográfica recoberta por floresta de mata atlântica. Revista do Instituto Florestal, São Paulo, v.5, n.1, p.1-20, 1993.

BRANCO, S.M. Hidrologia aplicada à engenharia sanitária. 3.ed. São Paulo: CETESB/ ASCETESB, 1986. $616 \mathrm{p}$.

CARVALHO, A.R.; MINGANTE, F.H.; TORNISIELO L. Relação da atividade agropecuária com parâmetros físicos e químicos da água. Revista Química Nova, São Paulo, v.23, n.5, p.618- 22, 2000.

CASTRO, P.S. Influência da cobertura florestal na qualidade da água em duas bacias hidrográficas na região de Viçosa - MG. 1980. 132 f. Dissertação (Mestrado em Hidrologia Florestal) - Escola Superior de Agricultura “Luiz de Queiroz”, Universidade de São Paulo, Piracicaba, 1980.

COUTO, L.; DUBÉ, F. The status and practice of forestry in Brazil at the beginning of the $21^{\text {st }}$ century: A review. The Forestry Chronicle, Ottawa, v.77, n.5, p.817-30, 2001.

ESTEVES, F.A. Fundamento da limnologia. Rio de Janeiro: Interciência/ FINEP, 1988. 575 p.

LEITE, F.P.; BARROS,N.F.; SANS, L.M.A.; FABRES, A.S. Regime hídrico do solo sob povoamento de eucalipto, floresta nativa e pastagem, na região de Guanhães - MG. Revista Árvore, Viçosa, v.21, n.4, p. 455-62, 1997.

LIMA, E.B.N.R. Modelagem integrada para gestão da qualidade da água na Bacia do Rio Cuiabá. 2001. 184 f. Tese (Doutorado em Recursos Hídricos) - Universidade Federal do Rio de Janeiro, Rio de Janeiro, 2001.

LIMA.W.P.; REICHARDT, K. Regime de água do solo sob floresta homogênea de eucalipto e de pinheiro. Piracicaba: CENA, 1987. 31 p. (Boletim Científico, 43).

MARGALEF, R. The place of epicontinetal waters in global ecology. In: MARGALEF, R. Limnology now: a paradigm of planetary problems. Amsterdam: Elsevier Science, 1994. p.1-8.

MATHEUS, C.E.; MORAES, A.J. de; TUNDISI, T.M.; TUNDISI, J.G. Manual de análises limnológicas. São Carlos: Centro de Recursos Hídricos e Ecologia Aplicada, USP, 1995. 62 p.

OLIVEIRA, F.A. Produção e qualidade da água em bacias hidrográficas contendo diferentes coberturas vegetais na região de agudos, São Paulo. 1989. 96 f. Dissertação (Mestrado em Hidrologia Florestal) - Escola Superior de Agricultura “Luiz de Queiroz”, Universidade de São Paulo, Piracicaba, 1989.

PALHARES, J.C.P.; SCANDOLERA, A.J.; LUCAS JÚNIOR, J.; COSTA, A.J. da. Monitoramento da qualidade da água do Córrego Jaboticabal através de parâmetros químicos. In: WORKSHOP DE INTEGRAÇÃO DE INFORMAÇÕES DA BACIA HODROGRÁFICA DO RIO MOGI GUAÇU, 3., 2000, Porto Ferreira. Anais... Porto Ferreira: Prefeitura Municipal de Porto Ferreira, 2000. p.43-4. 
PALMA-SILVA, G.M. Diagnóstico ambiental, qualidade da água e índice de depuração do Rio Corumbataí - SP. 1999. 155 f. Dissertação (Mestrado em Manejo Integrado de Recursos) - Centro de Estudos Ambientais, Universidade Estadual Paulista, Rio Claro, 1999.

PASSOS, C.A.M.; COUTO, L. Sistemas agroflorestais potenciais para o Estado do Mato Grosso do Sul. In: SEMINÁRIO SOBRE SISTEMAS FLORESTAIS PARA O MATO GROSSO DO SUL, 1997, Dourados. Resumos... Dourados: EMBRAPA-CPAO, 1997. p.16-22 (Documento, 10)

PETERS, N.E; MEYBECK, M. Water quality degradation effects on freshwater availability: impacts to human activities. Water International, Urbana, v.25, n.2, p.214-21, 2000.

PIRES, J.S.R.; SANTOS, J.E. dos. Bacias hidrográficas: integração entre meio ambiente e desenvolvimento. Ciência Hoje, São Carlos, v.19, n.10, p.4-45, 1995.

PORTO, F.A.; BRANCO, S.M.; LUCA, S.J. Caracterização da qualidade da água. In: PORTO, R.L. (Org.). Hidrologia ambiental, São Paulo: EDUSP, 1991. p.375-390.

RANZINI, M. Balanço hídrico, ciclagem de geoquímica de nutrientes e perdas de solo em duas microbacias reflorestadas com Eucaliptus saligna Smith, no vale do Paraíba, SP. 1990. $110 \mathrm{f}$. Dissertação (Mestrado em Hidrologia Florestal) - Escola Superior de Agricultura "Luiz de Queiroz", Universidade de São Paulo, Piracicaba, 1990.

RIZZI, N.E. Função da floresta na manutenção da qualidade da água para uso humano. Revista Florestal, São Carlos, p. 54-65, 1981.

SABARA, M.G. Comparação ecológica entre rios de menor ordem, drenando bacias cobertas por plantios agrícolas, pastagens e plantios de Eucalyptus grandis, na região do médio Rio Doce (MG) 1999. 259 f. Tese (Doutorado em Ecologia e Recursos Naturais) - Universidade Federal de São Carlos, São Carlos, 1999.

SRINGUETTI, A.G. Implantação e avaliação inicial de modelos de recuperação florestal em mata ciliar para proteção de trechos degradados do rio Mogi Guaçu (SP). 2001. 109 f. Dissertação (Mestrado em Biologia Vegetal) - Universidade Estadual Paulista, Rio Claro, 2001. 